\title{
Stress-Strain State of Wooden Columns Under Uneven Local Heating
}

\author{
Andrii Pelekh \\ Postgraduate. National University «Lviv Polytechnic» \\ http://orcid.org/0000-0002-0390-0915 (Lviv, Ukraine)
}

\begin{abstract}
The fire resistance of wooden structures is an important stage in the design of wooden structures. For many years, scientists around the world have been studying the behavior of a structure in a fire and trying to predict the consequences. In this work, the work of wooden compressed elements under the action of local heating is considered. The aim of the work is to find the effect of fire on a compressed element at any point of its crosssection using analytical methods. As the modern normative base recommends the use of approximate methods and empirical coefficients, it does not allow to estimate just approximately the work of a structural element during a fire and to take into account the non-uniform heating of the element's body. To solve the problem, we used the Heaviside mathematical functions and the system of discrete equations. As a result, dependences describing the change of strength and strain characteristics in any point of the element body during its local heating were obtained.
\end{abstract}

Keywords: wood, high temperature, wood columns, fire, fire design.

Постановка проблеми. У зв’язку із особливостями властивостей деревини, у випадку iii використання в якості несучої конструкції дуже важливо річ відіграє саме іiі вогнестійкість [1,2]. Також важливо є забезпечити деформативність дерев'яних конструктивних елементів у межах граничних значень. У даному випадку проблемою $є$ виявлення залежностей міцнісних і деформіних характеристик деревини, а саме урахування їх зменшення, при дії температури від іiі розміщення на тілі несучої конструкції та зміни .3 часом $[3,4]$.

Аналіз останніх досліджень та публікацій. Проблема зміни міцнісних та деформіних характеристик дерева під час дії високих температур, не є новою[5,6]. Також важливою є проблема втрати стійкості при зміні характеристик для стиснутих елементів [7-9]. Проте автори не змогли уникнути використання емпіричних коефіцієнтів, що пропонується у нормативній документації $[3,4]$.

Сучасні норми при уточнювальному розрахунку вимагають урахування цих залежностей [4]. Проте вплив даних факторів враховують із введенням емпіричних коефіцієнтів, що у свою чергу не дозволяють із достатньою точністю врахувати розподіл характеристик по тілу колони. Автором було виконано аналіз повзучих характеристик 
під час дії високих температуру [10], у цій же роботі подано пошуки аналітичними методами зміни характеристик під час одностороннього локального нагріву.

Постановка завдання. Отримати аналітичними методами розв'язки задач про розподіл міцнісних та деформівних характеристик, тим самим уникнути введення емпіричних коефіцієнтів в розрахунок.

\section{Виклад основного матеріалу.}

Для розв'язання даної задачі спочатку була виконана апроксимація міцнісних та деформівних характеристик. Для апроксимації були використанні дані із [4], що відображені на рис. 1 та рис.2.:

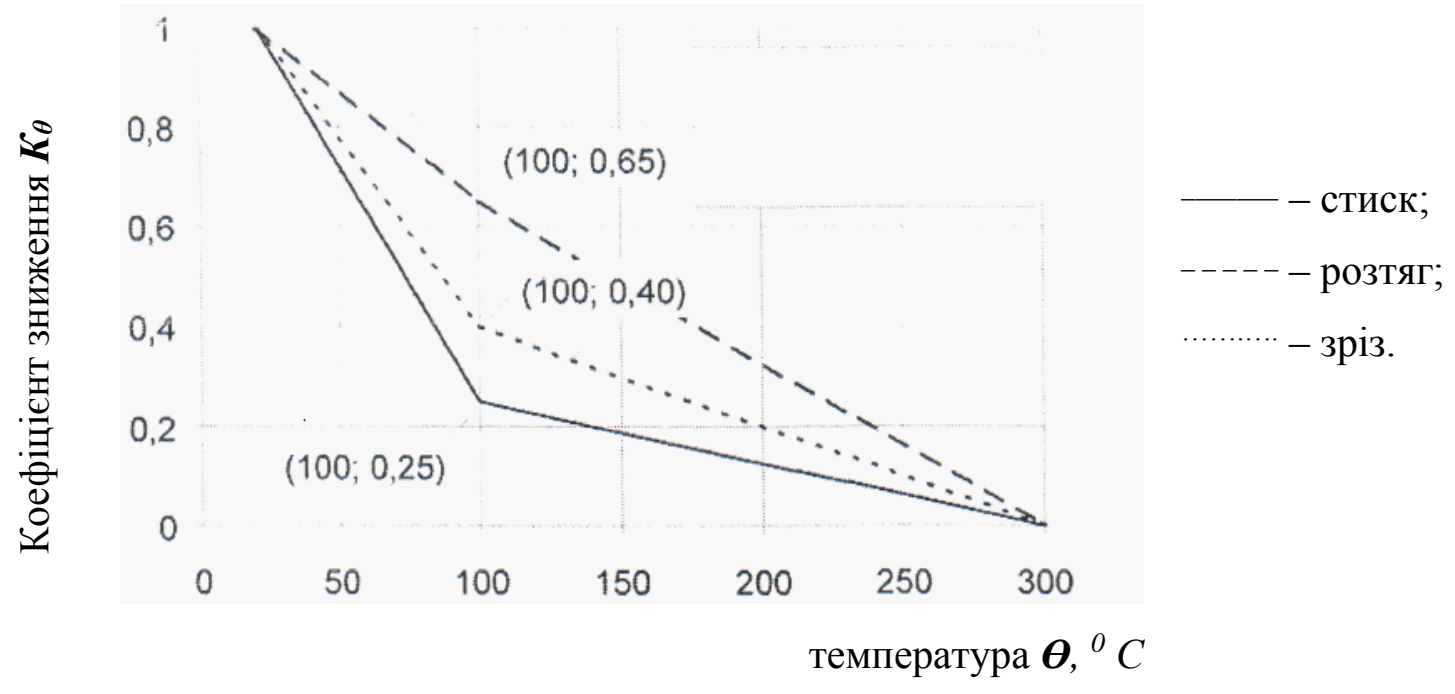

Рис. 1. Залежності зміни коефіцієнтів зниження міцності деревини на стиск, розтяг і зріз від температури.

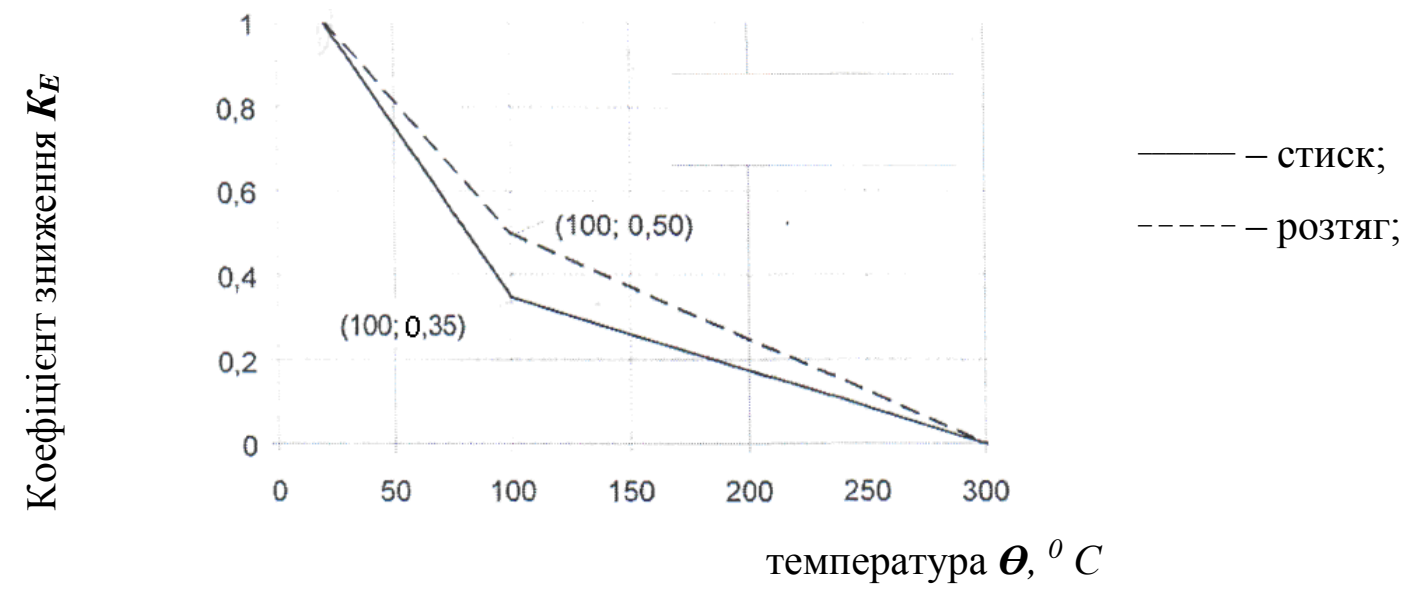

Рис. 2. Залежності зміни коефіцієнтів зниження модуля пружності деревини при стиску і розтягу від температури. 
Дані залежності несуть фізичний зміст співвідношення міцності (рис.1) та модуля пружності (рис.2), при певній температурі. Крім того ці залежності являються лінійними функціями 3 яскраво вираженими точками перегину при температурі $\theta=100{ }^{\circ} \mathrm{C}$. температури випаровування вільної води 3 деревини. Для їх апроксимації були використані ступінчасті функції Хевісайда [11]. 3 урахуванням цього залежності характеристик деревини мають вигляд (1):

$$
\left.\begin{array}{l}
k_{\theta, c}=[1-U(\theta-20)]+\left[\begin{array}{l}
U(\theta-20)- \\
-U(\theta-100)
\end{array}\right] \cdot\left[1-\frac{4,375}{1000} \cdot(\theta-20)\right]+ \\
+[U(\theta-100)-U(\theta-300)] \cdot[0,65-0,00325 \cdot(\theta-100)] ; \\
k_{\theta, t}=[1-U(\theta-20)]+\left[\begin{array}{l}
U(\theta-20)- \\
-U(\theta-100)
\end{array}\right] \cdot[1-0,0075 \cdot(\theta-20)]+ \\
+[U(\theta-100)-U(\theta-300)] \cdot[0,4-0,002 \cdot(\theta-100)] ; \\
k_{\theta, v}=[1-U(\theta-20)]+\left[\begin{array}{l}
U(\theta-20)- \\
-U(\theta-100)
\end{array}\right] \cdot\left[1-\frac{9,375}{1000} \cdot(\theta-20)\right]+ \\
+[U(\theta-100)-U(\theta-300)] \cdot\left[0,25-\frac{1,25}{1000} \cdot(\theta-100)\right] .
\end{array}\right\}
$$

де:

$k_{\theta, c}=\frac{f_{c, \theta}}{f_{c, 20}}$ - коефіцієнт зміни міцності деревини на стиск при температурі $\theta$;

$k_{\theta, t}=\frac{f_{t, \theta}}{f_{t, 20}}-$ те ж, на розтяг при температурі $\theta$;

$k_{\theta, v}=\frac{f_{v, \theta}}{f_{v, 20}}-$ те ж, на зріз при температурі $\Theta$;

$f_{\mathrm{c}, \theta}, f_{t, \theta}, f_{v, \theta}$ - фактичні міцності деревини на стиск, розтяг та зріз при температурі $\theta$ відповідно;

$f_{c, 20}, f_{t, 20}, f_{v, 20^{-}}$те ж, при температурі $20{ }^{\circ} C$;

$U(\mathrm{x})$ - функція Хевісайда [11];

$\theta \equiv \theta(x, y, z, t)$ - температура в розрахунковій точці колони.

Були також отримані залежності коефіцієнтів зміни модуля деформації деревини від температури (2):

$$
\left.\begin{array}{l}
k_{E, c}=[1-U(\theta-20)]+\left[\begin{array}{l}
U(\theta-20)- \\
-U(\theta-100)
\end{array}\right] \cdot[1-0,00625 \cdot(\theta-20)]+ \\
+[U(\theta-100)-U(\theta-300)] \cdot[0,5-0,0025 \cdot(\theta-100)] ; \\
k_{E, t}=[1-U(\theta-20)]+\left[\begin{array}{l}
U(\theta-20)- \\
-U(\theta-100)
\end{array}\right] \cdot[1-0,008125 \cdot(\theta-20)]+ \\
+[U(\theta-100)-U(\theta-300)] \cdot[0,35-0,00175 \cdot(\theta-100)] .
\end{array}\right\}
$$


Де, $k_{\mathrm{E}, \mathrm{c}}=\frac{\mathrm{E}_{\mathrm{c}, \theta}}{\mathrm{E}_{\mathrm{c}, 20}}-$ коефіцієнти зміни модуля деформації деревини для стиску при температурі $\theta$;

$k_{\mathrm{E}, t}=\frac{\mathrm{E}_{t, \theta}}{\mathrm{E}_{t, 20}}-$ те ж, для розтягу при температурі $\theta$;

$E_{c, \theta}, E_{t, \theta}$ - фактичні модулі деформації деревини для стику і розтягу при температурі $\theta$ відповідно;

$E_{\mathrm{c}, 20}, E_{t, 20}$ - те ж, при температурі $20{ }^{\mathrm{O}} \mathrm{C}$.

Отримані теоретичні залежності зміни міцності та модуля деформації деревини від температури нагріву дозволили визначити міцність і модуль деформації в будь-якій точці колони як функцію від температури.

Для спрощення обчислень (яке дозволяється при інженерних розрахунках), схеми для розрахункових перетинів були представлені у вигляді ступінчастої лінії (рис.3) по ширині перерізу колони b.

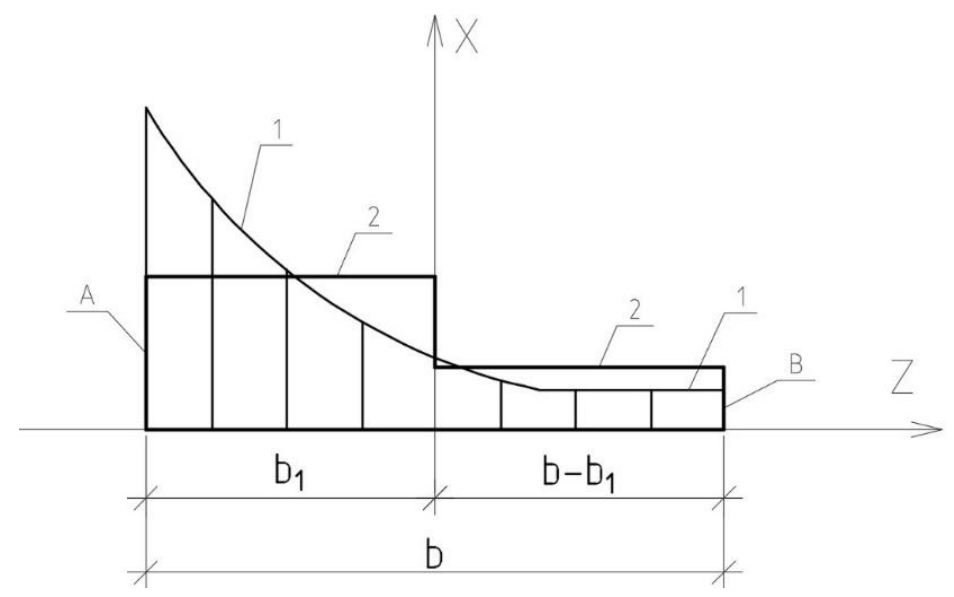

Примітка. Вісь «0Х» збігається з нейтральною віссю колони по висоті

Рис. 3. До апроксимації фактичних епюр ступінчастою лінією.

1 - фактична епюра; 2 - те ж, апроксимація.

Тому необхідно приводити до середнього значення температури і температурних залежностей в деякому об'ємі з координатами центру заданого шару матеріалу (це необхідно при використанні для вирішення поставленого завдання методу кінцевих елементів) і в деякому перетині колони з координатою «Х». 3 урахуванням сказаного і представленої на рис.3, схеми для довільного перерізу маємо:

1. Для визначення температури: 


$$
\left.\begin{array}{l}
\bar{T}=\frac{\int_{-D x / 2}^{D x / 2} \int_{-D y / 2}^{D y / 2} \int_{-D z / 2}^{D z / 2} T(x, y, z, t) \cdot d x \cdot d y \cdot d z}{D x \cdot D y \cdot D z} \\
a_{T}=\frac{\int_{0}^{h} \int_{0}^{b_{1}} T(x, y, z, t) \cdot d z \cdot d y}{b_{1} \cdot h} ; \\
b_{T}=\frac{\int_{0}^{h} \int_{b-b_{1}}^{b} T(x, y, z, t) \cdot d z \cdot d y}{\left(b-b_{1}\right) \cdot h}
\end{array}\right\}
$$

2. Для міцності деревини на стиск:

$$
\left.\begin{array}{l}
\bar{f}_{c}=\frac{\int_{-D x / 2}^{D x / 2} \int_{-D y / 2}^{D y / 2} \int_{-D z / 2}^{D z / 2} f_{c}(x, y, z, t) \cdot d x \cdot d y \cdot d z}{D x \cdot D y \cdot D z} ; \\
a_{f_{c}}=\frac{\int_{0}^{\square} \int_{0}^{b_{1}} f_{c}(x, y, z, t) \cdot d z \cdot d y}{b_{1} \cdot h} ; \\
b_{f_{c}}=\frac{\int_{0}^{\square} \int_{b-b_{1}}^{b} f_{c}(x, y, z, t) \cdot d z \cdot d y}{\left(b-b_{1}\right) \cdot h} ;
\end{array}\right\}
$$

3. Для міцності деревини на розтяг:

$$
\left.\begin{array}{rl}
\bar{f}_{t} & =\frac{\int_{-D x / 2}^{D x / 2} \int_{-D y / 2}^{D y / 2} \int_{-D z / 2}^{D z / 2} f_{t}(x, y, z, t) \cdot d x \cdot d y \cdot d z}{D x \cdot D y \cdot D z} \\
a_{f_{t}} & =\frac{\int_{0}^{h} \int_{0}^{b_{1}} f_{t}(x, y, z, t) \cdot d z \cdot d y}{b_{1} \cdot h} \\
b_{f_{t}} & =\frac{\int_{0}^{h} \int_{b-b_{1}}^{b} f_{t}(x, y, z, t) \cdot d z \cdot d y}{\left(b-b_{1}\right) \cdot h}
\end{array}\right\}
$$

4. Для міцності деревини на зріз:

$$
\left.\begin{array}{l}
\bar{f}_{v}=\frac{\int_{-D x / 2}^{D x / 2} \int_{-D y / 2}^{D y / 2} \int_{-D z / 2}^{D z / 2} f_{v}(x, y, z, t) \cdot d x \cdot d y \cdot d z}{D x \cdot D y \cdot D z} \\
a_{f_{v}}=\frac{\int_{0}^{h} \int_{0}^{b_{1}} f_{v}(x, y, z, t) \cdot d z \cdot d y}{b_{1} \cdot h} ; \\
b_{f_{v}}=\frac{\int_{0}^{h} \int_{b-b_{1}}^{b} f_{v}(x, y, z, t) \cdot d z \cdot d y}{\left(b-b_{1}\right) \cdot h} ;
\end{array}\right\}
$$

5. Для модуля пружності деревини на стиск: 


$$
\left.\begin{array}{l}
\bar{E}_{c}=\frac{\int_{-D x / 2}^{D x / 2} \int_{-D y / 2}^{D y / 2} \int_{-D z / 2}^{D z / 2} E_{c}(x, y, z, t) \cdot d x \cdot d y \cdot d z}{D x \cdot D y \cdot D z} ; \\
a_{E_{c}}=\frac{\int_{0}^{\square} \int_{0}^{b_{1}} E_{c}(x, y, z, t) \cdot d z \cdot d y}{b_{1} \cdot h} ; \\
b_{E_{c}}=\frac{\int_{0}^{\square} \int_{b-b_{1}}^{b} E_{c}(x, y, z, t) \cdot d z \cdot d y}{\left(b-b_{1}\right) \cdot h} ;
\end{array}\right\}
$$

6. Для модуля пружності деревини на розтяг:

$$
\left.\begin{array}{l}
\bar{E}_{t}=\frac{\int_{-D x / 2}^{D x / 2} \int_{-D y / 2}^{D y / 2} \int_{-D z / 2}^{D z / 2} E_{t}(x, y, z, t) \cdot d x \cdot d y \cdot d z}{D x \cdot D y \cdot D z} ; \\
a_{E_{t}}=\frac{\int_{0}^{\square} \int_{0}^{b_{1}} E_{t}(x, y, z, t) d z \cdot d y}{b_{1} \cdot h} ; \\
b_{E_{t}}=\frac{\int_{0}^{\square} \int_{b-b_{1}}^{b} E_{t}(x, y, z, t) d z \cdot d y}{\left(b-b_{1}\right) \cdot h} ;
\end{array}\right\}
$$

Висновки. Отримано аналітичний розв'язок задачі про розподіл міцностей деревини на стиск, розтяг та зріз в тілі нерівномірно, одностороньо нагрітої дерев'яної колони. В цьому випадку слід підставити розраховані за рівняннями температурні поля та отримані залежності для коефіцієнта зміни міцності деревини.

Отримано аналітичний розв'язок задачі що до деформаційних властивостей (модуля деформацій) при стиску і розтязі в перетинах нерівномірно нагрітої дерев'яної колони. В цьому випадку слід підставити розраховані температурні поля та отримані залежності для коефіцієнта зміни модуля деформацій деревини.

\section{References}

1. Shnal T. Vohnestiikist ta vohnezakhyst derevianykh konstruktsii: Navchalnyi posibnyk. [Fire resistance and fire protection of wooden structures: Textbook.] Lviv: Vydavnytstvo NU "Lvivska politekhnika," 2006. 220 p.

2. DBN V.2.6-161:2017. Dereviani konstruktsii. Osnovni polozhennia. [Wooden structures. Substantive provisions.] Kyiv: Minrehionbud Ukrainy, 2017. P. 111.

3. EN 1995-1-2:2004. Eurocode 5: Design of timber structures. - Part 1-2: General Structural fire design.

4. DSTU-N-P B V.2.6-157:2010 Konstruktsii budynkiv $i$ sporud. Proektuvannia derev ianykh konstruktsii. Chastyna 1-2. Zahalni polozhennia. Rozrakhunok konstruktsii na vohnestiikist [Constructions of buildings and structures. Design of wooden structures. Part 1- 
2. Terms. Calculation of structures for fire resistance] (EN 1995-1-2:2004, MOD). Kyiv: Minrehionbud Ukrainy, 2010.

5. Lau P.W.C., Zeeland I. V. Modelling the char behavior of structural timber // Proceedings of the Fire and Materials. 1998. P. 123-135.

6. Haksever A., Savaş S. Design of wood columns under real fire action. 2005. Vol. 16. P. 3713-3738.

7. Homon S. Kryterii ruinuvannia pozatsentrovostysnutykh ta zghynalnykh elementiv $z$ derevyny $z$ urakhuvanniam pruzhnoplastychnoi roboty materialu $z$ obmezhenoiu deformatyvnistiu // Resursoekonomni materialy, konstruktsii, budivli ta sporudy. [Criterion of destruction of eccentrically compressed and bending elements of wood, taking into account the elastic-plastic work of the material with limited deformability // Resource-saving materials, structures, buildings and structures] 2013. P. 248-253.

8. Kúdela J., Slaninka R. Stability of wood columns loaded in buckling. Part 2. Eccentric buckling // Drev. Vysk. Res. 2004. Vol. 49. P. 13-23.

9. Escalantea M., Rougier V., Rosales M.B. Buckling of wood columns with uncertain properties. Mecánica Computacional Vol XXXI, 2012. P. 2735-2744.

10. Pelekh A. The question of modeling the creep behavior of wood under high ambient temperatures // Sci. Eur. 2018. Vol. 2, № 25. P. 40-44.

11. Korn H., Korn T. Spravochnyk po matematyke. [Handbook of Mathematics.] Moskva, 1974. $840 \mathrm{p}$.

\section{Translation of the Title, Abstract and References to the Author's Language}

\section{Анотація}

Вогнестійкість дерев'яних конструкцій є важливим етапом проектування дерев'яних споруд. Уже багато років вчені всього світу досліджують поведінку споруди під час пожежі та намагаються спрогнозувати наслідки. У даній роботі розглянено роботу дерев'яних стиснутих елементів при дії локального нагріву. Метою роботи є за

допомогою аналітичних методів знайти вплив пожежі на стиснутий елемент у будь якій точці його перерізу. Оскільки сучасна нормативна база рекомендує використання наближених методів та емпіричних коефіцієнтів, що не дозволяє лиш наближено оцінити роботу конструктивного елементу під час пожежі, та врахувати нерівномірний нагрів тіла елементу. Для розв'язування задачі було використано математичні функції Хевісайда та системи дискретних рівнянь. У результаті отримано залежності які 
описують зміну міцнісних та деформативних характеристик у будь які точці тіла елементу при локальному його нагріві.

Ключові слова. дерево, високі температури, дерев'яні колони, пожежа, протипожежне проектування.

\section{Список посилань}

1. Шналь Т. Вогнестійкість та вогнезахист дерев'яних конструкцій: Навчальний посібник. Львів: Видавництво НУ “Львівська політехніка,” 2006. 220 р.

2. ДБН В.2.6-161:2017. Дерев’яні конструкції. Основні положення. Київ: Мінрегіонбуд України, 2017. Р. 111.

3. EN 1995-1-2:2004. Eurocode 5: Design of timber structures. - Part 1-2: General Structural fire design.

4. ДСТУ-Н-П Б В.2.6-157:2010 Конструкції будинків і споруд. Проектування дерев `яних конструкцій. Частина 1-2. Загальні положення. Розрахунок конструкцій на вогнестійкість (EN 1995-1-2:2004, MOD). Київ: Мінрегіонбуд України, 2010.

5. Lau P.W.C., Zeeland I. V. Modelling the char behaviour of structural timber // Proceedings of the Fire and Materials. 1998. P. 123-135.

6. Haksever A., Savaş S. Design of wood columns under real fire action. 2005. Vol. 16. P. 3713-3738.

7. Гомон С. Критерій руйнування позацентровостиснутих та згинальних елементів 3 деревини 3 урахуванням пружнопластичної роботи матеріалу 3 обмеженою деформативністю // Ресурсоекономні матеріали, конструкції, будівлі та споруди. 2013. P. 248-253.

8. Kúdela J., Slaninka R. Stability of wood columns loaded in buckling. Part 2. Eccentric buckling // Drev. Vysk. Res. 2004. Vol. 49. P. 13-23.

9. Escalantea M., Rougier V., Rosales M.B. Buckling of wood columns with uncertain properties. Mecánica Computacional Vol XXXI, 2012. P. 2735-2744.

10. Pelekh A. The question of modeling the creep behavior of wood under high ambient temperatures // Sci. Eur. 2018. Vol. 2, № 25. P. 40-44.

11. Корн Г., Корн Т. Справочник по математике. Москва, 1974. 840 р. 